Images vol. XIII/no. 22

\section{Magic, Emotions and Film Producers: Unlocking the "Black-box" of Film Production}

For some time now behind-the-scenes documentaries and interviews with directors, cinematographers and editors, whose aim is to shed some light on the process of making a film or a TV series, have proliferated on special DVD editions. This is not an isolated phenomenon as historically some feature films have had filmmaking as its main theme and emphasised a certain mystic surrounding the process of filmmaking; François Truffaut's Day for Night (1973), Jean-Luc Godard's Contempt (1963), Nicholas Ray's In the Lonely Place (1950), Vincente Minnelli's The Bad and the Beautiful (1952), Federico Fellini's Eight and a half (1963), Abbas Kiarostami's Close up (1990), Spike Jonze's Adaptation (2002) and Robert Altman's The Player (1992) are among such films. Often these films focus on the figure of a producer, a demanding, grumpy, and unsympathetic individual, who happens to have a very poor grasp of the creative process over which he (it is always a "he" in these films) presides.

For the purposes of this article I will not treat the producers (executive, line, creative, studio or independent) as a separate professional group. Instead, I will see them as participants in the creative process of filmmaking and try to understand their place within this process. My contention is that much of the misunderstanding of the role of the producers stems from our misconception of the process of filmmaking which needs to be presented in the terms which will take it beyond the "hands-on" accounts found in countless "how-to-do" manuals. I will be thus discussing the process of production as such while making some suggestions regarding the reasons for the complex dynamics determining the producers' role in the process, and a sense of disengagement that they seem to have from it.

Although a certain, quite often carefully crafted, image of the filmmaking process is mediated to the audiences through various practitioners' diaries, interviews and voice-over commentaries which configure the spectators' experience of cinema, and to a less extend of television, this process has not really played an important part in various paradigms associated with film criticism or with the academic study of cinema. Usually, a critical reflection or academic analysis of films begins when their making ends. This means that most critics and scholars think about the films from the position of a spectator, thus emphasising the social and cultural perspective linked to film reception rather than to film production. At the same time little effort seems to

\section{Introduction}


go towards establishing a conceptual link between the processes of filmmaking and the aesthetic object that is film, resulting from these processes. In his recent book Production Culture: Industrial Reflexivity and Critical Practice in Film and Television John Thornton Caldwell emphasizes the fact that his anthropologically- and ethnographically-informed perspective focussed on the analysis of the self-reflexive discourses generated by the below-the-line television workers in Hollywood ultimately must be linked to the textual analysis of film. [1] Yet he never shows how such a link might be actually forged.

The work of historians, such as David Bordwell, Kristin Thompson and Janet Staiger, and their The Classical Hollywood Cinema: Film Style and Mode of Production to 1960 is an important and welcome exception here, as is the work of various British and French historians[2] Yet, this engagement with production through historical and archival sources begs a question as to why the examination of filmmaking processes as a contemporary phenomenon has been of less interest. Are the reasons associated with the fact that this type of study calls for a different set of methodologies - such as conducting extensive interviews or using observational techniques employed by ethnographers, anthropologists, sociologists and geographers? Or, is the reason not so much methodological as it is conceptual? Might it be that we don't understand yet how to see a film as shaped by its process of production, as a representation of this process as opposed to the representation of reality, and how to bridge the practice of film practitioners with the practice of the spectators?

In my work I have been focussing on this conceptual problem trying to find ways of closing the gap between film production and film reception. Seeing images in terms of the process of their production means, among other things, revisiting the cultural paradigm, which is linked to technology and the culture of the machine, without which cinema, or photography, simply cannot exist. Integrating the process of filmmaking into our concept of cinema is also about accounting for the production cultures which determine the origins and the making of a film. These cultures are often seen as distant from the culture of reception even though the two are not really that distinct, with the exception of the critical or academic re-evaluation of films which are not made in the contemporary period. In the case of contemporary films the cultures of production and reception often overlap as it is evident with some trade journalists who are often the same people who write film reviews and criticism in specialist film magazines and general press.

[1] J.T. Caldwell, Production Culture: Industrial Reflexivity and Critical Practice in Film and Television, Duke University Press, Durham and London 2008.

[2] D. Bordwell, K. Thompson, J. Staiger, The Classical Hollywood Cinema: Film Style and Mode of Production to 1960, Routledge, London 1985; T. Bergfelder,
S. Harris, S. Street, Film Architecture and the Transnational Imagination. Set Design in 193os European Cinema, University of Amsterdam Press, Amsterdam 2007; I. Christie, The Art of Film: John Box and Production Design, Wallflower Press, London 2009. 
The existing studies of film production were conducted by anthropologists, sociologists, and economists, working mostly in the Background United States - outside of the discipline of film studies (and by researchers who were interested in American film industry). The shared characteristic of these studies is that they all focus on social aspects of the institution of cinema and in this way redefine our understanding of what cinema is beyond the existing frameworks informed to a large extend by cultural studies. How is then cinema defined as an object of study by social scientists? (1) In some studies the emphasis is on the impact of films on the audiences; (2) in other studies the emphasis is on the community of filmmakers which make films, and the ways in which they are connected and interact with each other. The first category of studies is quite a familiar territory and dates back to the Payne Fund Studies (1929-1932) commissioned by the US government.[3] The Payne Fund Studies explored the impact of motion pictures on audiences, in particular, youth, using social science methods such as experimental studies, survey research techniques, interviews and content analysis. Such studies continue to be conducted, with a very recent one commissioned in the UK by the UK Film Council on the cultural impact of the British Cinema entitled "Stories We Tell Ourselves: The Cultural Impact of UK Film 1946-2006." [4] What links The Payne Fund Studies with the UK Film Council report is the understanding that new methods of investigation (including the analysis of the viewers-related data available on the internet) are required in order to assess the impact of motion pictures on the wider society and its particular groups.

The Payne Fund Studies were also motivated by the growing interest in Hollywood as an industry, which was perceived as very wealthy with the salaries of filmmakers and producers skyrocketing. The US film industry was vertically integrated, a huge source of exports for the US and financially backed by the Wall Street. Leo Rosten's Hollywood: the Movie Colony, the Movie Makers was the first study of the individuals employed in the film industry, how their work was regulated and how they were remunerated for their work. [5] His study was mostly based on questionnaires circulated to producers, actors, directors, writers, editors and research workers.

Rosten's study was followed by a very detailed investigation Hollywood, the Dream Factory: an Anthropologist Looks at the Movie-makers which drew on the anthropological methodology in which its author, Hortense Powdermaker, was well-versed.[6] In both Rostens and Powdermaker's study the emphasis was on a community of

[3] Payne Fund, Committee on Educational Research, Motion Pictures and Youth, The Payne Fund Studies, New York 1933.

[4] Birkbeck, Media Consulting Group and Narval Media, Stories We Tell Ourselves: The Cultural Impact of UK Film 1946-2006. A Study for the UK Film
Council, UK Film Council, London 2010.

[5] L. Rosten, Hollywood: the Movie Colony, the Movie Makers, Harcourt, Brace, and Co., New York 1941.

[6] H. Powdermaker, Hollywood, the Dream Factory: an Anthropologist Looks at the Movie-makers, Little, Brown, and Co., Boston 1950. 
individuals, employees and owners of the Hollywood studios, and the social basis for their interaction. In her study Powdermaker focuses on writers, directors, actors, executives and people in the front office, who are either the creative talent or the "gate-keepers." In her view the employees form a social system, which influences both the content and the meaning of the movies. In other words, her main goal was to explain how "the system underlying the production of movies influences them." [7] In her view the whole Hollywood system was geared towards shaping its main product, which she describes as "story-telling."

What is difficult to discern from either Rosten's or Powdermaker's study is the relationship between the functioning of this filmmaking community and the result of their work (i.e. films they actually make). Powdermaker establishes this relationship in very broad-terms by seeing a film as an imprint of the reality of the filmmakers and the social system, which they form, as film professionals. This is a very interesting point, but she does not explain how this "imprinting" actually happens. Bordwell's, Thompson's and Staiger's study of the changes in the work of the filmmaking community leading to the creation of the Hollywood classical style is not only a distant echo of Powdermaker's argument, but also an attempt to close the gap between the makers and the outcome of their labours. However, their study is focused on the particularities of one production culture and attempts to explain a development of one particular "style." The question thus remains as to whether we could develop a broader way of thinking about film production, which would allow us to establish a model in which the images and the process in which they are generated are considered together. In search for the answers to this question let us now turn to the writings of a philosopher Vilém Flusser and a sociologist Bruno Latour.

\section{The "black-box" of image-making}

[7] Ibidem, p. 9.
In his book Towards a Philosophy of Photography Vilém Flusser discusses photography in relation to the history of writing and sees the two as distinct steps in the development of culture.[8] Whilst writing is historical, linear and rational, photography is magical, linked to imagination and two-dimensional. Flusser refers to photographs as "technical images," which unlike paintings or frescoes, result from the "machine-operator" complex whose operation is not understood and for this reason labelled as a "black-box".

The significance (of the technical images) appears to flow into the complex on the one side (input) in order to flow out on the other side (output), during which the process - what is going on within the complex - remains concealed: a "black box" in fact. The encoding of technical images, however, is what is going on in the interior of this black box and consequently any criticism of technical images must be aimed 
at an elucidation of its inner workings. As long as there is no way of engaging in such criticism of technical images, we shall remain illiterate.[9]

Flusser suggests that only by unlocking the "black box" and by engaging with the process of making images, will we be able to decode the images and thus render them comprehensible. Flusser's view is closely related to that of Latour who describes his idea of the "blackbox" of science in the following terms:

The word "black box" is used by cyberneticists whenever a piece of machinery or a set of commands is too complex. In its place they draw a little box about which they need to know nothing but its input and output. As far as John Whittaker is concerned the double helix and the machine are two black boxes. That is, no matter how controversial their history, how complex their inner place, how large the commercial or academic networks that hold them in place, only their input and output count.[10]

For Latour the creation of scientific facts and the way in which a machine is constructed and operated, are both a kind of a black box. If we think about our encounter with a film (let's say the one which employs certain special effects, or is innovative in another way, for instance because of the performances that it gets from the actors, or the camera and editing work, which result in a new style, like the Dogme 95 films), this film presents itself to as the Latourian or Flusserian "black box." We don't know how to make such a film ourselves, we are not aware of the effort and history behind it, we are only concerned at this stage in the output (that is the film itself). Most of the reception of the film will focus on the output and will ignore the actual process - the "black box."

The next step which Latour makes in his argument is to try to open the "black box" and to outline the history of the process which made a scientific fact. Interestingly enough, he talks about opening the "black box" as opening the Pandora's box, which indicates that this is a difficult and problematic venture. Opening the "black box," means a different way of thinking about scientific facts, which emphasises their social dimension and the act of constructing and assembling the fact. For instance, for Latour a computer chip, or a piece of equipment (i.e. a camera) is an "organisation" (of people who thought it up, described it, promoted it, etc), a "bureaucracy" (all the paperwork and the power structures and hierarchies it implies), and a "minimisation of risks" (how to make it work better; or how to make it a successful commercial venture). If we then follow Latour's line of reasoning we could think about the end product, not in the ways it was named, labelled and packaged for us, or in the ways which are implied by its usage; rather we define this object not as an object but as a social process with its own history and its own dynamics. Latour illustrates this point with the following example:

"Suspense," "game," "tone," "delay of publication," "awe," “six week delay" are not common words for describing a molecular structure. This is the case

[9] Ibidem, p. 16.

[10] B. Latour, Science in Action: How to Follow Scien- tists and Engineers through Society, Harvard University Press, Cambridge 1987, pp. 2-3. 
once the structure is known and learned by every student. However, as long as the structure is submitted to a competitor's probing, these queer words are part and parcel of the very chemical structure under investigation.[11]

What is the stage then at which film could be still thought about not in terms of its title, or the quotes from the critics appearing on a poster, but in the terms which imply the process of making which is not yet finished? When is the process of filmmaking scrutinised? When does the probing of the film happen? It can occur at different stages of the filmmaking process. Let's think back to the moment when the very idea of the film is conceived and the film is pitched by a script-writer or a director to a producer. We probably have a treatment and a script by then. There is an object then which is not a film yet, even though it may include some visualisations. When the film enters the process of pre-production, its nature changes yet again. It is no longer a pitch or a script, but a collection of stills made by a still-board artist; when it moves to the production - delays which have to do with the weather or the absence of the actors - allow us to think of this film simply as the "delay."

But when does a film become a rarefied object akin to the scientific fact in its solidity and certainty? Is it at the moment of the film release? Or, is it at the moment when we have a film physically in the box, or when we are watching a final cut or a remastered version? Is it when we read a critique of a film, either in a magazine or in a scholarly publication, which reaffirms its cultural, aesthetic and social value? Or is it when we are sufficiently distant from the context in which the film was made and don't have to bother with it but simply watch the film as part of film history for instance, rather than as an example of social history or history of technology?

Latour postulates that in order to understand the science-in-making it is necessary to go to the laboratory and follow the scientists at work. This means that we need to concentrate mostly on the material rather than symbolic aspects of production in the cultural field which is cinema. The first question would be then - what does a laboratory consist of? (Some expensive equipment, which allows the scientists to conduct a particular set of experiments, people with a particular expertise, a set of ideas for generating the experiments). Is it possible to think of film production as a laboratory? (A studio, a set, people brought together to work on location, moving production to a different location for post-production). The interaction of humans and equipment is very important and it has a place both on the set and in the lab. This dependency on technology is something that both worlds share.

Latour treats the whole lab (including humans and non-humans) as an instrument which produces an inscription or a graph. For him this inscription, being the visual result of a scientific experiment, is what the labs are all about. This is how he describes this whole lab with all its participants being a one institution:

[11] Ibidem, p. 6. 
A statistical institution which employs hundreds of pollsters, sociologists and computer scientists gathering all sorts of data on the economy is an instrument if it yields inscriptions for papers written in economic journals with for instance a graph of the inflation rate by month and by branch of industry. No matter how many people were made to participate in the construction of the image, no matter how long it took, no matter how much it cost, the whole institution is used as one instrument.[12]

If we follow this line of reasoning we could think of people working in film production together on a set as an instrument too; a kind of a big machine consisting of both human and non-human parts which work together creating an inscription, a record of their work, which is the film itself. Latour comes up with an idea of describing this instrument in terms of actor-network (where actors can be both human and non-human). The idea is that everything done on the set is an example of mediation which happens through a different set of equipment. This allows us to emphasise technical and technological element of filmmaking. Machines are the human extension, in the same way that the humans can be seen as extensions of certain machines. Many thinkers have taken the idea of Latour farther, beyond the human-machine hybrid, and extended it into the interactions between humans and the material world. This idea has potentially some very interesting implications for film production. For example we could think about this relationship from the perspective of actors and actresses, who are hybridised and transformed because of the interaction of their person with costumes, make up, set design, lights and finally - the camera lens. There are also more obvious examples of film practitioners entering a relationship with technology; it is enough to think about lighting, cameras, and editing suites. Every one of these practitioners of course also has a particular relationship with the materiality of the set where the shoot happens. Latourian focus on the material workings and the operation of the lab is his way of unlocking the "black box" of scientific facts. It could also be our way of advancing new understanding of films and their various production cultures.

The interaction between humans and technology thus emerges as key to our understanding of the process of film production. Flusser refers to this interaction as an "apparatus" of which a camera is an important but crucially not the only example. There also "those apparatuses that, on the one hand, assume gigantic size, threatening to disappear from our field of vision (like the apparatus of management) and, on the other, shrivel up, becoming microscopic in size so as to totally escape our grasp (like the chips in electronic apparatuses)." [13] The film producer is part of the "apparatus" of filmmaking but it is the "apparatus of management" of which s/he is part. In a way s/he might be as removed from the actual "machine-operator complex" (camera,

"A different kind of magic" - producers and creatives 
lights, make-up, editing, etc) as those who develop scientific texts which form basis on which film cameras are actually manufactured. In other words, the problem with film producers has to do with their actual input into the filmmaking "black-box." They appear to be part of a different "black-box," which is removed from the "black-box" of shooting the film and editing it.

The ways in which Flusser and Powdermaker use the term "magic" in relation to the process of photographic and filmmaking, respectively, sheds an additional light on the place of the producer in the process. Flusser argues that photographic images have "the specific ability to abstract surfaces out of space and time and to project them back into space and time what is known as 'imagination."' [14] This time and space

[...] specific to the image is none other than the world of magic, a world in which everything is repeated and in which everything participates in a significant context [...]. For example in the historical world sunrise is the cause of the cock's crowing; in the magical one, sunrise signifies crowing and crowing signifies sunrise. The significance of images is magical.[15]

Importantly, this "magical" aspect of photographic of cinematic images does not just result from the artist's consciousness but is dependent on the apparatuses - technological, social and others.

Powdermaker thinks of the "magic" of filmmaking in quite different terms. The ideology, which is the "glue" of the whole Hollywood system together, is based on "magical thinking" embraced by the employees. This is linked to the unpredictability of the success of any Hollywood film and the idea of "breaks" and "luck." She sees the whole system as a gambling den in which the human resources at the disposal (people's talent; people's skills) are used very poorly, and where excessive emphasis are put on money and the power of one set of individuals over another (executives over writers; directors over actors, etc). The system is also gripped by fear and uncertainty regarding its profits, thus dehumanised. At the same time she argues that just like "primitive" societies the Hollywood "colony" tries to contain the fear of its environment and the threat of the financial loss through a series of controls among which there are big business, big profits, big salaries, censorship, the star system, and "what the audience wants." All these control mechanisms leave their marks on the movies in the same way that shamanic practices of South-Pacific communities shape and mark their cultural artefacts. [16]

Whilst the creatives are certainly a party to and experience the kind of magical thinking Powdermaker describes, the producers rarely participate in the kind of creative "magic" associated with the production of images which Flusser talks about. What is then a common denominator for the producers and creatives involved in a filmmaking

[14] Ibidem, p. 9.

[15] Ibidem. 
process? In conclusion I would like to propose a set of hypothesis, which will go some way to answering this question.

We often hear that the power of films lays in their emotional impact. In recent years, some corners of film studies have been preoccupied with the investigation of the senses and the body, which could be related to the view of films in terms of emotions and affect.[17] Much of the filmmaking process rests on creating and communicating this emotional power of the films. Instead of thinking, like Powdermaker did, that the film workers are collectively involved in story-telling, or like Bordwell, Thompson and Staiger, that they are preoccupied with the generation of a particular style of filmmaking, I would like to argue that films are collectively involved in generating, assembling and crafting the emotion of the film.

In the last ten years theorists working in the sub-section of management studies, called organisational science, have been interested in seeing organisations as "emotional arenas" and in the ways in which "our work lives are mediated and shaped by material objects [...] and how we often invest such objects and spaces with emotional qualities, reflecting our own identities and moods." [18] Fineman refers in particular to the work of his colleagues, Gagliardi and Strati, who researched the impact of aesthetics as vehicles for emotional response. Fineman writes, "such emotional and aesthetic experiences have been examined, where the aesthetic captures feelings of form or flow experienced from the places and objects where people work. The machines, office layout, colours, geographical setting, noise, music, task activities, foods are objects of sound, sight, touch or smell that trigger feelings: rightness, discord, warmth, harshness or alienation." [19] We could rethink the emotional aspects involved in the process of filmmaking seen in terms of organisation of individuals interacting not just with each other but also with materiality of the set. And then we could try to re-establish how this emotional material is inscribed into the body of the film, or perhaps creating the body of the film, the source of filmic emotions. To think about filmmaking process in terms of senses, emotions and affect will also help us rethink this process in gender terms, and, hopefully, to become more sensitive towards cultural variations which make the filmmaking process different depending on its cultural context. To conclude, the magic of cinema is in the emotions experienced not only by the spectators but also by their makers during the process of film-production.

The article was previously published in the internet journal Wide Screen, vol. 2, issue 2, 2010 .

[17] L. Marks, The Skin of the Film: Intercultural Cinema, Embodiment, and the Senses, Duke University Press, Durham and London 200o; Th. Elsaesser, M. Hagener, Film Theory: An Introduction through the Senses, Routledge, London 2009.

\section{Conclusion}

